\title{
Perceptions and Barriers of Hands Hygiene Practice among Medical Science Students in a Medical School in Malaysia
}

\author{
Al-Naggar RA ${ }^{a}$, Al-Jashamy $\mathrm{K}^{\mathrm{b}}$ \\ a Population Health and Preventive Medicine, Faculty of Medicine, UiTM, Malaysia \\ ${ }^{b}$ Faculty of Medicine, SEGi University, Malaysia
}

\begin{abstract}
Introduction: Hand hygiene is the single, most critical measure for reducing the risk of transmitting organisms to patients and health care providers. To our knowledge, none of such study on Malaysian university student exists in the literature. Therefore, the objective was to explore the perceptions and barriers of hand's hygiene practice among university students. Methods: Focus group discussion conducted in January-2010 among 40 medical science students from Management and Science University (MSU). Simple random sampling was used, and the ethics were obtained from participants. The students were divided into five focus groups; the number of each group ranged between 8-10 members. The data obtained were classified into various categories, and the data was analyzed manually. Results: The majority of the participants mentioned that they frequently washed their hands using soap. Some of the participants washed the hands only with plain water. However, the majority of the participants mentioned that the laziness was their main barrier of frequent hand washing, followed by lack of nearby water supply and then the feeling that their hands are not dirty enough to be infected. The majority of the participants agreed that hand washing is clinically significant in reducing the spread of infectious diseases; some of them disagreed. The Majority of the participants knew the hand washing technique in the university. Conclusion: Medical science students still have some misconception and negative attitude towards hand hygiene practice. Multidisciplinary strategies needed to improve hand hygiene among students.
\end{abstract}

KEYWORDS: Perception, barrier, hand hygiene, universities, students

\section{INTRODUCTION}

Hand hygiene is considered one of the most important infection control measures for preventing healthcareassociated infections. ${ }^{1}$ It is recognized as the leading measure to prevent cross-transmission of microorganisms and to reduce the occurrence of health care-associated infections. ${ }^{2,3}$ Hand hygiene also is critical in the prevention of hospital acquired infections, which contribute to death of nearly 90,000 hospital patients per year and $\$ 4.5$ billion in medical expenses. ${ }^{4}$ Improving hand hygiene practices globally is a priority for the World Health Organization. ${ }^{5}$ Although hand hygiene is a very simple procedures and has long been considered one of the most important infection control measures for prevention, compliance rates by healthcare workers with recommended hand hygiene procedures was generally reported to be below $50 \% .2,3,6-8$ The recommendation on hand hygiene has

Corresponding Author:

Professor Dr. Karim Al-Jashamy,

Professor of Pathology, Faculty of Medicine

SEGI U, Malaysia

Email: jashamy@yahoo.com been updated, and hand washing has been replaced by hand-rub as the standard of care. ${ }^{2,3,5}$ It has been suggested that the optimal duration of hand washing is between 30 seconds and one minute as a minimum and a maximum range respectively. ${ }^{9}$ It is also demonstrated that alcohol-based hand antiseptics are used worldwide for their rapid antimicrobial effects, broad-spectrum coverage, better tolerability, and ease of application. ${ }^{9}$

Risk factors for non-adherence have been extensively studied, , 2,3,7,10-12 and physicians have been repeatedly observed as being poor compliers. ${ }^{2,3,7,8,13}$ While there is an extensive discussion in the literature about potential interventions to improve hand hygiene in the United States of America and Europe, research from developing countries like Malaysia are less common. This study has been conducted to explore the perceptions and barriers of hand's hygiene practice among university students. To our knowledge, this is the first of such studies in Malaysia.

\section{MATERIALS AND METHODS}

This focus group discussion was conducted in January of the academic year 2010 among 40 medical science students from International Medical School, Management and Science University, Shah Alam, Malaysia. The study explored student's perceptions and opinions towards hand hygiene practice and their 
views on barriers towards hand washing. Simple random sampling was used. The participants were on sixth semester of their study and of different age groups, and both sexes were included. The interviews were conducted in English Language. The study was approved by the ethics committee of the Management and Science University. Consent was obtained from all participants. The students were divided into five focus groups; the number of each group is between 8-10 members. The main author of this study was the facilitator for the focus group discussion. The facilitator asked probe questions and directed the group discussion in which all students participated and were given equal time for discussion. The conversations during the discussion were written down in order to analyze the main theme of the study. The focus group discussion started with an ice breaking in which every participant introduced him/her self, age and race to the rest of the group. Then questions were asked regarding hand hygiene practice, which included: the practice of hand washing in daily life, clinical setting, and barriers of hand hygiene practice. The data obtained were classified into various categories and was analyzed manually.

\section{RESULTS}

The majority of the participants mentioned that they did the hand washing frequently specially before and after meals, before and after outdoor activities and after the toilet.

"I wash my hand very often, before and after having meal, after cleaning, gardening and going to the toilet." (Malay, Female)

The majority of the participants used soap to wash their hands. Some of them washed hands only with plain water.

"I wash my hands mostly with plain water, unless after use the toilet, I use soap." (Malay, Female)

"I usually use water and soap or hand sanitizer and tissue paper." (Malay, Female)

Regarding barriers of frequent hand washing, the majority of the participants mentioned that the laziness was the main reason for not washing hands, followed by lack of nearby water supply and then the feeling that their hand is not dirty enough to get infected.

"Sometimes, I feel lazy to wash my hands, or I feel my bathroom and the kitchen is too far from my room and also no source of water supply." (Malay, Female)

"When I am busy or whenever I thought that my hands not dirty enough to cause me infection." (Malay, Male)

"The barriers for not washing the hand frequently are: laziness and hand washing consume time." (Indian, Female)
"When busy with my work, I forget to wash the hands." (Indian, Female)

"I did not wash my hand frequently because most of the time away from home and never carry sanitizer along." (Indian, Female)

\section{Is hand washing clinically significant in preventing the spread of the infectious disease?}

The majority of the participants agreed that hand washing is clinically significant in reducing the spread of the infectious disease.

"Hand washing can kill most of the bacteria from transmitting." (Indian Female)

"Hand washing is clinically significant because hands are the main part which is directly in contact with others; hand washing can break the chain of infection." (Malay, Female)

"I don't think that washing hand is clinically significant to prevent spread the infectious disease." (Malay, Male)

"Hand washing is clinically significant in preventing the infectious diseases because there are many microorganisms on our hands that can cause infections." (Malay, Female)

\section{Technique for hand washing}

Majority of the participants knew the 7-step hand washing.

Majority of them knew about it from the university; few of them knew about it from school and TV.

"The hand would be wet under the running pipe water for 2 seconds. Rubbing for nearly 5 seconds, then apply soap, then wet and rub hands for 7 seconds. Finally wash under running water while rubbing the hand, I learn this technique from the TV."(Indian, Female)

"There is either surgical or medical hand washing. I learn it from bio-ethics and nursing class and also from the media and TV." (Malay, Female)

"The steps are:(1) wash hands with water, (2) apply soap all over the hands, (3) do scrubbing between fingers, palm and the back of the hands (4) wash with clean water (5) use dry and clean towel to dry the hands." (Malay, Male)

\section{Hand washing in clinical practice}

Majority of the participants mentioned that they practiced hand washing after dealing with patients. 


\section{DISCUSSION}

In this study, the majority of the participants mentioned that the barriers of not practicing hand washing are lacked of time. Similar findings were reported among health-care workers who mentioned that high workload was associated with non-adherence to hand hygiene. ${ }^{2,3,7,14-16}$ In this study, the majority of the participants mentioned that they did hand washing frequently specially before and after meals, before and after outdoor activities and after the toilet. Despite the positive attitude and high self-evaluation of hand hygiene behavior, they made no attempt to observe their own behavior. This is consistent with the notions of high self-assessment and over reporting that are well established in the literature. ${ }^{17-22}$ Hand hygiene can be performed by washing hands with plain soap and water. ${ }^{23}$ The use of a persistent level antimicrobial hand washing or an alcohol hand rubs is also acceptable. Drying of hands with tissue or electronic hand dryer is an important aspect of hand hygiene. In this study, the majority of the participants used soap to wash their hands. Some of them washed their hands only with water. Similar findings were reported among dentists and dental students, in which $80 \%$ of the participants washed their hands with soap and water and only $2.9 \%$ of the respondents used antiseptic preparations. ${ }^{23}$ Unacceptable practice of hand washing with water alone was reported among $17.1 \%$ of the respondent. This further reflects passive practice among the studied health professionals. ${ }^{22,23}$

Research studies comparing the effects of soap and antiseptics in reducing hospital costs due to consequences of poor hand hygiene of health care personnel have been conducted in clinical areas. In addition, research on which antiseptic solution gives better results had also been conducted. ${ }^{24}$ Bulus and Kaleli ${ }^{25}$ investigated the effects of antiseptic solutions that are preferred by health care personnel. Girou et al. ${ }^{9}$ and Zaragoza et al. ${ }^{26}$ reported that alcohol-based solutions are more effective for hand washings.

There are number of known factors affecting compliance with hand hygiene. Some of these are lack of time, forgetfulness, lack of knowledge of importance of hand hygiene in preventing cross infection, poor access to hand washing facilities, lack of institutional commitment and skin irritation to hand hygiene products. ${ }^{27-29}$ In this study, the majority of the participants mentioned that the laziness is the main barrier of frequent hand washing, followed by lacked of nearby water supply and then feeling that their hands were not dirty enough to get infected. Similar findings reported that the main barriers to regular hand hygiene were lacked of adequate facilities, forgetfulness and lack of time. ${ }^{23}$ Lack of time has also been cited as a barrier to hand hygiene among nursing students. ${ }^{29}$ In other studies, the major reasons for inappropriate hand washing among nurses included work overload, insufficient sinks, patients' general condition, and inaccessibility of hand-washing agents. ${ }^{11,} 29-32$
The majority of the participants agreed that hand washing is clinically significant in reducing the spread of the infectious disease; some of them disagreed. Similar findings reported by Omogbai et al. ${ }^{23}$ who stated that the majority of the respondents knew that hand washing is important. This may indicate the potential willingness of the participants to carry out hand hygiene in the future. It has been emphasized that hygienic hand washing must be performed before and after patient contact; before invasive procedures; before taking care of patients considered to be infected; before and after contact with wounds, urinary, and similar catheters; after contact with patients' secretions; and before and after wearing gloves. ${ }^{33}$ The majority of the participants in this study mentioned that they practiced hand washing after dealing with the patients. Similar finding was reported by Anwar et al. ${ }^{34}$ in which that participant's adherence to hand hygiene after caring for a patient was mentioned; whereas poorer adherence was reported "before" having direct contact with a patient. This might be due to lack of knowledge of hand hygiene guidelines. Similar finding was reported among nurse students who washed their hands before and after patient contact. ${ }^{35}$

\section{CONCLUSIONS}

Despite the high knowledge of the role of hand washing in the prevention of cross infection, there is inadequate hand washing practices. There is a need for educational and motivational intervention to target university students, mostly in the form of seminars and pamphlets, which can be used for educational purposes. There is also a need, at the university level, to provide hand hygiene facilities, and eliminate barriers to hand washing. It is recommended that further studies should be conducted to investigate whether nursing students improve their hand-washing practices by putting knowledge into practice when working in the clinical area. Furthermore, our study highlights the need for improving knowledge of behavior determinants among nursing students.

\section{REFERENCES}

1. Yuan CT, Dembry LM, Higa B, et al. Perceptions of hand hygiene practices in China. J Hosp Infect 2009; 71:157-62.

2. Pittet $D$, Hugonnet $S$, Harbarth $S$, et al. Effectiveness of a hospital-wide programme to improve compliance with hand hygiene. Infection Control Programme. Lancet 2000; 56:1307-12.

3. Boyce JM, Pittet D, Healthcare Infection Control Practices Advisory Committee, Society for Healthcare Epidemiology of America, Association for Professionals in Infection Control, Infectious Diseases Society of America Hand Hygiene Task Force. Guideline for Hand Hygiene in Health-Care Settings. Recommendations of the Healthcare Infection Control Practices Advisory Committee and the HICPAC/SHEA/APIC/IDSA Hand Hygiene 
Task Force. Infect Control Hosp Epidemiol 2002; 23:S3-40.

4. Hand hygiene resources. Available at: http:// www.handhygiene.org/. Accessed 27th December, 2010.

5. WHO World Alliance for Patient Safety. Guidelines on hand hygiene in health care advanced draft a summary: Clean hands are safer hands. World Health Organisation 2005 (Online). Available at: URL: http: / / whqlibdoc. who.int/hq/2005/WHO_ EIP_SPO_QPS_05.2.pdf. Accessed 2009 February 20).

6. Lankford MG, Zembower TR, Trick WE, et al. Influence of role models and hospital design on hand hygiene of healthcare workers. Emerg Infect Dis 2003; 9:217-223.

7. Pittet D, Mourouga P, Perneger TV. Compliance with hand-washing in a teaching hospital. Infection Control Program. Ann Intern Med 1999; 130:126-30.

8. Albert RK, Condie F. Hand-washing patterns in medical intensive-care units. N Engl J Med 1981; 304:1465-6.

9. Girou E, Loyeau S, Legrand P, Oppein F, Brun Boisson C. Efficacy of hand-rubbing with alcohol based solution versus standard hand washing with antiseptic soap: Randomised clinical trial. BMJ 2002; 17:325-362.

10. Dubbert PM, Dolce J, Richter W, Miller M, Chapman SW. Increasing ICU staff hand washing: effects of education and group feedback. Infect Control Hosp Epidemiol 1990; 11:191-3.

11. Kretzer EK, Larson EL. Behavioral interventions to improve infection control practices. Am J Infect Control 1998; 26:245-253.

12. Larson E, Killien M. Factors influencing hand washing behavior of patient care personnel. Am J Infect Control 1982; 10:93-9.

13. Raju TN, Kobler C. Improving handwashing habits in the newborn nurseries. Am J Med Sci 1991; 302:355-8.

14. Pittet D, Ste' phan F, Hugonnet S, et al. Hand-cleansing during postanesthesia care. Anesthesiology 2003; 99:530-35.

15. Bittner MJ, Rich EC, Turner PD, Arnold WH. Limited impact of sustained simple feedback based on soap and paper towel consumption on the frequency of hand washing in an adult intensive care unit. Infect Control Hosp Epidemiol 2002; 23:120-6.

16. Hugonnet S, Perneger TV, Pittet D. Alcohol-based handrub improves compliance with hand hygiene in intensive care units. Arch Intern Med 2002; 162:1037-43.

17. O’Boyle C, Henley S, Larson E. Understanding adherence to hand hygiene recommendations; the theory of planned behaviour. Am J Infect Control 2001; 29:352-60.

18. Alexander KM, Sirotnak N. Self-reported handwashing practices of Idaho State University physical therapy graduates. J Phys Therapy Ed 1997; 11:3-9.
19. Larson E, Bryan J, Adler L, Blane C. A multifaceted approach to changing hand washing behavior. Am J Infect Control 1997; 25: 3-10.

20. Tibballs J. Teaching hospital medical staff to hand wash. Med J Aust 1996; 164:395-398.

21. Alvaran M, Butz A, Larson, E. Opinions, knowledge, and self-reported practices related to infection control among nursing personnel in long-term care settings. Am J Infect Control 1994; 22:367-370.

22. Henry K, Campbell S, Collier P, Williams CO. Compliance with universal precautions and needle handling and disposal practices among emergency department staff at two community hospitals. Am J Infect Control 1994; 22:129-137.

23. Omogbai JJ, Azodo CC, Ehizele AO, Umoh A. Hand hygiene amongst dental professionals in a tertiary dental clinic. African Journal of Clinical and Experimental Microbiology 2011; 12:9-14.

24. Sharir R, Teitler N, Lavi I, Raz R. High-level hand washing compliance in a community teaching hospital: A challenge that can be met!. J Hosp Infect 2001; 49:55-8.

25. Bulus N, Kaleli I. Comparison of antibacterial effects of different antiseptics after hand washing. Mikrobiyol Bul 2004; 38:137-43. [Turkish]

26. Zaragoza M, Salle's M, Gomez J, Bayas JM, Trilla A. Hand washing with soap or alcoholic solutions? A randomized clinical trial of its effectiveness. Am J Infect Control 1999; 27:258-61.

27. Giles BK, Chisholm CD, Cordell WH, Nelson DR. Hand washing frequency in an emergency department. Ann Emerg Med 1994; 23:1307-12.

28. Patarakul K, Tan-Khum A, Kanha S, Padungpean $D$, Jaichaiyapum 00. Cross-sectional survey of hand-hygiene compliance and attitudes of health care workers and visitors in the intensive care units at King Chulalongkorn Memorial Hospital. J Med Assoc Thai 2005; 88:287-93.

29. Barrett R, Randle J. Hand hygiene practices: nursing students' perceptions. J Clin Nurs 2008; 17:1851-7.

30. Jumaa, PA. Hand hygiene: Simple and complex. Int J Infect Dis 2005; 9:3-14.

31. Kampf G, Kramer A. Epidemiologic background of hand hygiene and evaluation: Important agents for scrubs and rubs. Clin Microbiol Rev 2004; 17: 863-93.

32. Pittet D, Simon A, Hugonnet S, et al. Hand hygiene among physicians: Performance, beliefs, and perceptions. Ann Intern Med 2004; 141:1-8.

33. Çelik S, Koçaș S. Hygienic hand washing among nursing students in Turkey. Appl Nurs Res 2008; 4:207-11.

34. Anwar MA, Rabbi S, Masroor M, et al. Self-reported practices of hand hygiene among the trainees of a teaching hospital in a resource limited country. J Pak Med Assoc 2009; 59:631-4.

35. Rodriguez MA, Novalbos Ruiz JP, Martinez Nieoto JM, Baraza Jimenez I, Costa Alonso M. Hospital infections. Risky practices of nursing students. Rev Enferm 1999; 22:678- 684. [Spanish] 